\title{
Stroke Volume
}

National Cancer Institute

\section{Source}

National Cancer Institute. Stroke Volume. NCI Thesaurus. Code C94989.

The difference in a cardiac ventricle's blood capacity taken at times of minimum and maximum blood content. This is end diastolic volume less end systolic volume. 